\title{
PROTOCOLO: COLOCACIÓN Y RETIRADA DEL EQUIPO DE PRO- TECCIÓN PERSONAL (EPP) PARA LA ATENCIÓN DE PACIENTES CON COVID-19. HOSPITAL REGIONAL LAMBAYEQUE
}

\author{
Pablo D. Villegas-Cruz ${ }^{1, a}$, Oscar M. Cusman-Aguilar ${ }^{1, b}$, Diana P. Vásquez-Acosta 1,c
}

\section{RESUMEN}

Objetivos. El virus SARS-CoV-2 se transmite a través de contacto y gotas por eso diferentes organizaciones y asociaciones de salud sugieren el uso adecuado del equipo de protección personal (EPP) para la atención de los pacientes con esta patología. Por tal motivo, la elaboración de protocolos es importante para disminuir la transmisión del virus desde cualquier fuente, asimismo permite uniformizar criterios sobre el manejo de los EPP teniendo en consideración los recursos que cuenta el Hospital Regional Lambayeque; además verificar la correcta colocación y retiro de los EPP al ingreso y salida de las unidades de atención al paciente con Covid-19, a través de las listas de chequeo con el fin de disminuir o mitigar errores.

Palabras clave: Equipo de protección Personal, Covid-19.(Fuente: DeCS-BIREME).

\section{PROTOCOL: PLACEMENT AND WITHDRAWAL OF THE PERSONAL PROTECTION EQUIPMENT (PPE) FOR THE CARE OF PATIENTS WITH COVID-19. HOSPITAL REGIONAL LAMBAYEQUE}

\section{ABSTRACT}

Objectives. The SARS-CoV-2 virus is transmitted through contact and drops, which is why different organizations and health associations suggest the proper use of personal protective equipment (PPE) for the care of patients with this pathology. For this reason, the elaboration of protocols is important to reduce the transmission of the virus from any source, and it also makes it possible to standardize criteria for the management of PPE, taking into account the resources available at the Lambayeque Regional Hospital; also verify the correct placement and removal of PPE upon entry and exit of patient care units with Covid-19, through checklists in order to reduce or mitigate errors.

Keywords: Personal protective equipment, Covid-19. (Source: MeSH-NLM)

\footnotetext{
${ }^{1}$ Unidad de Cuidados Intensivos, Hospital Regional Lambayeque. Lambayeque, Perú.

a Médico Cirujano. Especialista en Medicina Intensiva y de Emergencia. Especialista en Medicina General Integral

${ }^{\mathrm{b}}$ Licenciado en Enfermería. Especialista en Cuidados Intensivos.

c Magister en Enfermería. Especialista en Cuidados Intensivos.
} 


\section{INTRODUCCIÓN}

A principios de diciembre de 2019 , se identificaron los primeros casos de neumonía de origen desconocido en Wuhan, la capital de la provincia de Hubei (1). El patógeno ha sido identificado como un nuevo betacoronavirus de ARN envuelto que actualmente se ha denominado coronavirus 2 del síndrome respiratorio agudo severo (SARS-Cov-2), que tiene una similitud filogenética con el SARS-Cov ${ }^{(2)}$.

Dado el brote de coronavirus del síndrome respiratorio agudo severo (SARS-Cov) en 2002 y el brote de coronavirus del síndrome respiratorio de Oriente Medio (MERS-CoV) en $2012{ }^{(3)}$, nCoV-2019 es el tercer coronavirus que emerge en la población humana en las últimas dos décadas, una emergencia que ha puesto a las instituciones de salud pública en alerta máxima.

La Organización Mundial de la Salud (OMS) ha declarado recientemente que la enfermedad por coronavirus 2019 (Covid-19) es una emergencia de salud pública de preocupación internacional (4).

El nuevo virus ahora llamado SARS-Cov-2, que causa la enfermedad Covid-19 se trasmite de persona a persona a través del contacto cercano, gotas respiratorias y por transmisión aérea. Sin embargo, los procedimientos como la intubación orotraqueal, nebulizaciones, entre otros; aumentan el riesgo de transmisión aérea. Por cuanto la necesidad de utilizar los Equipos de protección personal (EPP) busca disminuir la transmisión desde cualquier fuente, teniendo en consideración los recursos con lo que cuenta el Hospital Regional Lambayeque ${ }^{(5)}$. Así mismo, iniciar una base de datos estadística basados en las listas de chequeo para adoptar las medidas necesarias encaminadas a mejorar la protección del personal asistencial en la atención a los pacientes sospechosos e infectados con el SARS-Cov-2 ${ }^{(6)}$.

El plan de contingencia de la Sociedad Peruana de Medicina Intensiva (SOPEMI) en su acápite disposiciones generales tanto para la atención de los casos probables y confirmados de neumonía grave por Covid-19 que requieren ventilación artificial mecánica (VAM), como los que no la requieran promulga el uso de los equipos de protección personal como una medida de protección del personal de asistencia sanitaria; considerando estos mismos como de uso obligatorio ${ }^{(7)}$.

Las sociedades médicas uruguayas recomiendan como regla general en todos los escenarios de atención el uso de los EPP, enfatizando la provisión adecuada y capacitación del uso de los mismos con el fin de minimizar los riesgos de transmisión al personal sanitario ${ }^{(8)}$.

El personal que tome las muestras clínicas, atienda o traslade a casos en investigación, probables o confirmados o las personas que entren a la habitación de aislamiento (per- sonal sanitario y no sanitario), deberán llevar un equipo de protección personal para prevenir la transmisión de la infección. En el caso de pacientes pediátricos o que requieran acompañamiento, el acompañante deberá adoptar las medidas necesarias para su protección mediante la utilización de equipos de protección personal ${ }^{(9)}$.

PROTOCOLO: COLOCACIÓN DEL EQUIPO DE PROTECCIÓN PERSONAL (EPP) PARA LA ATENCIÓN DE PACIENTES CON COVID-19. (Adaptación de las instrucciones de la OMS sobre de uso de EPP para Ébola)

\section{CONSIDERACIONES PREVIAS:}

- Los EPP deberán ser usados para la atención de todo caso sospechoso de covid-19.

- En la atención de los casos de pacientes con síntomas respiratorios no sospechosos se utilizará mascarilla quirúrgica tanto el personal asistencial como el paciente.

- La colocación de los EPP debe realizarse en una habitación fuera de la unidad de atención del paciente con Covid-19.

- Se recomienda realizar este procedimiento en pareja para verificar su correcta colocación, a través de lista de chequeo. Mientras uno se va vistiendo el otro debe ir comprobando que cada paso se haga correctamente.

- El personal con cabello largo traerlo recogido. Y colocarse el gorro quirúrgico.

- Los varones deben estar afeitado.

- Previamente ir al sanitario, realizar las funciones fisiológicas y colocarse chaqueta y pantalón de tela identificados.

- Retirarse joyas: aretes, collares, anillos, relojes, pulseras u otro objeto que se encuentre en sus dedos, manos o muñecas.

- No llevar nada en los bolsillos (lapiceros, celular, etc.).

- Ajustarse el calzado

- Si el personal usa lentes para visión ajustarlos adecuadamente. De preferencia con cinta adhesiva a la frente.

\section{PROCEDIMIENTO:}

1. Realizar el lavado clínico de las manos con agua y clorhexidina al $2 \%$ por 40 a 60 segundos, de acuerdo a protocolo de la OMS: seguir los 11 pasos obligatoriamente.

2. Colocarse el mandilón impermeable (mameluco): Abrir el mameluco, verificar que este en buen estado, colocarse empezando por las extremidades inferiores y luego las superiores, subir el cierre hasta el pecho sin ajustar el gorro. 
3. Calzarse los guantes de nitrilo o látex sin talco, asegurarse que cubran los puños del mameluco.

4. Colocarse la Mascarilla (FFP2, FFP3, P100, N95 o respirador personal) cubriendo nariz, mentón y cara; colocar una liga por encima de las orejas y la otra por debajo de las mismas en el caso de las mascarillas. Probar que no haya fugas, inhalando y exhalando. Puede considerar la colocación de apósito hidrocoloide a la altura de tabique nasal para evitar laceraciones por el tiempo de exposición a la mascarilla.

5. Colocarse los lentes protectores sobre el puente nasal de la mascarilla (si usas lentes de visión, estos deben quedar bajo los lentes protectores). En su defecto estamos usando lentes tipo nitro.

6. Ajustarse adecuadamente el gorro del mameluco hacia la cara. Este gorro va a cubrir los sujetadores de lentes y mascarilla.

7. Colocarse una bata impermeable en su defecto estéril sobre el mameluco. Debe quedar suelta, cómoda y anudarla con nudo simple.

8. Calzarse otro par de guantes de nitrilo o látex sin talco encima.

9. Colocarse el protector facial.

10. Una segunda persona deberá verificar el sellado correcto del traje.

11. Ingresar a la unidad de atención al paciente y cerrar la puerta.

NOTA: Durante la atención al paciente no debe recolocarse nada. por eso la importancia de la correcta colocación de los EPP.

PROTOCOLO: RETIRADA DEL EQUIPO DE PROTECCION PERSONAL (EPP) PARA LA ATENCIÓN DE PACIENTES CON COVID-19. (Adaptación de las instrucciones de la OMS sobre de uso de EPP para Ébola)

\section{CONSIDERACIONES PREVIAS}

- El retiro de los EPP deberá realizarse exclusivamente en una zona negra separada, a la salida de las unidades de atención de los pacientes con covid-19. Debidamente organizada según los flujogramas establecidos de los servicios de atención.

- Esta zona debe tener contenedores debidamente rotulados para el descarte del material desechable o reutilizable, según sea el caso.

- Esta zona debe tener un contenedor con detergente enzimático.

- Debe tener alcohol gel para higienización de manos.

- El retiro de los EPP se realizará de manera calmada y se- rena. De preferencia frente a un espejo.

- Fuera de las unidades de atención, junto a la puerta de las duchas deberá existir contenedores debidamente rotulados para desechar las mascarillas y ropa quirúrgica reutilizable según sea el caso.

\section{PROCEDIMIENTO}

1. Dirigirse a la zona asignada para el retiro de los EPP.

2. Higiene de manos con solución hidroalcohólica con guantes puestos.

3. Retirar bata impermeable. Primero se desata el lazo posterior y luego el lateral siempre teniendo cuidado de no tocar la parte delantera, se baja la bata hasta el pecho, se retira tirando de la parte interior, se enrolla y se deposita en el contenedor con bolsa roja.

4. Higiene de manos con solución hidroalcohólica con guantes puestos.

5. Retirarse el protector facial.

6. Higiene de manos con solución hidroalcohólica con guantes puestos

7. Abrir cuidadosamente el cierre del mameluco por completo, y sin tocar la parte internadesde arriba hacia abajo. Después de sacarse el overol de los hombros, quítese los guantes externos al mismo tiempo que saca los brazos de las mangas. Con los guantes internos puestos, enrolle el overol, desde la cintura hacia abajo y desde adentro hacia afuera, incluidas las botas; después apártese del overol y deséchelo de una manera segura.

8. Higiene de manos con solución hidroalcohólica con guantes puestos.

9. Retírese el protector facial y los lentes de protección reutilizables y colóquelos en el contenedor con detergente enzimático para su posterior desinfección.

10. Higiene de manos con solución hidroalcohólica con guantes puestos.

11. Retírese la mascarilla tocando sólo las ligas en la parte posterior de la cabeza y deseche la mascarilla de una manera segura en caso de ser descartable. En el caso de respirador personal colóquelo en el contenedor con detergente enzimático después de haberle quitado debidamente los filtros para su posterior desinfección.

12. Higiene de manos con solución hidroalcohólica con guantes puestos.

13. Quítese los guantes cuidadosamente con la técnica apropiada y deséchelos de una manera segura.

14. Retirarse de la zona negra. 
NOTA:

- La ropa de tela usada debajo del mameluco por normas de bioseguridad se lavará dentro de la institución.

- Personal sanitario debera bañarse antes de ir a casa.

- Si el personal va ir a almorzar este debera realizar el protocolo de retirada del epp y utilizar uno nuevo.

Conflictos de interés: Declaro no haber conflicto de intereses pertinentes

Fuentes de financiamiento: El presente artículo no tuvo fuentes de financiamiento externas

\section{REFERENCIAS BIBLIOGRÁFICAS}

1. Huang $\mathrm{C}$, Wang $\mathrm{Y}$, Li $X$, et al. y col. Clinical features of patients infected with 2019 novel coronavirus in Wuhan, China. Lancet 2020; 395: 497-506.

2. Zhu N, Zhang D, Wang W, et al. A novel coronavirus from patients with pneumonia in China, 2019. N Engl J Med 2020; 382: 727-733.

3. de Wit E, van Doremalen N, Falzarano D, Munster VJ. SARS y MERS: recent insights into emerging coronaviruses. Nat Rev Microbiol 2016 ; 14: 523-534

4. World Health Organization. Coronavirus disease (COVID-19) outbreak (https://www.who.int. opens in new tab)

5. Documento técnico: Atención y manejo clínico de casos COVID-19. Ministerio de Salud Perú 2020

6. Presentación: prevención y control de infecciones y nuevo coronavirus (CVID-19): precauciones estándares y uso de quipos de protección personal. OPS [Internet] 2020 Feb Available from: https://www.paho.org/es/ documentos/presentacion-prevencion-control-infecciones-nuevo-coronavirus-covid-19-precauciones

7. Plan de contingencia para el manejo de la infección grave por Covid-19 en los departamentos o servicios de cuidados críticos. Versión 01. Sociedad Peruana de Medicina Intensiva (SOPEMI) 2020.

8. Recomendaciones conjuntas para el manejo clínico de la infección por SARS-Cov-2 y la enfermedad COVID-19. Sociedad de Infectología Clínica de Uruguay (SICU) y Sociedad Uruguaya de Medicina Intensiva (SUMI) 2020 .

9. Ávila de Tomás J. F. Coronavirus COVID-19; patogenia, prevención y tratamiento. 2da edición. País Vasco: Salusplay editorial; 2020. 


\section{COLOCACIÓN DEL EQUIPO DE PROTECCIÓN PERSONAL (EPP) PARA LA ATENCIÓN DE PACIENTES CON COVID-19 \\ CUMPLIMIENTO OBLIGATORIO}

DATOS DEL PERSONAL ASISTENCIAL EVALUADO NOMBRES Y APELLIDOS:

OCUPACIÓN:

FECHA:

\begin{tabular}{|c|c|c|c|c|}
\hline \multirow{2}{*}{\multicolumn{2}{|c|}{ ITEMS A EVALUAR }} & \multicolumn{2}{|c|}{ CUMPLE } & \multirow[t]{3}{*}{ OBSERVACIÓN } \\
\hline & & SI & NO & \\
\hline 1 & CONSIDERACIONES PREVIAS & & & \\
\hline 2 & $\begin{array}{l}\text { Se lava las manos con agua y clorhexi- } \\
\text { dina al } 2 \% \text { según protocolo institucional. }\end{array}$ & & & \\
\hline 3 & $\begin{array}{l}\text { Se coloca mandilón impermeable (ma- } \\
\text { meluco): Abre el empaque, verifica que } \\
\text { está en buen estado, se coloca empezan- } \\
\text { do por las extremidades inferiores y luego } \\
\text { las superiores, sube el cierre. }\end{array}$ & & & \\
\hline 4 & $\begin{array}{l}\text { Se calza los guantes de nitrilo o látex sin } \\
\text { talco cubriendo los puños del mameluco, } \\
\text { una segunda persona sella con cinta ad- } \\
\text { hesiva de papel esta unión. }\end{array}$ & & & \\
\hline 5 & $\begin{array}{l}\text { Se coloca la mascarilla (FFP2, FFP3, } \\
\text { P100 o en su defecto N95) cubriendo na- } \\
\text { riz, mentón y cara; coloca una liga por en- } \\
\text { cima de las orejas y la otra por debajo de } \\
\text { las mismas. Prueba que no haya fugas, } \\
\text { inhalando y exhalando. }\end{array}$ & & & \\
\hline 6 & $\begin{array}{l}\text { Se coloca los lentes protectores sobre } \\
\text { el puente nasal de la mascarilla (si usa } \\
\text { lentes de visión, estos quedan bajo los } \\
\text { lentes protectores). }\end{array}$ & & & \\
\hline 7 & $\begin{array}{l}\text { Se ajusta adecuadamente el gorro del } \\
\text { mameluco hacia la cara, tratando de te- } \\
\text { ner un sellado completo, no deben que- } \\
\text { dar áreas expuestas de piel. }\end{array}$ & & & \\
\hline 8 & $\begin{array}{l}\text { Colocarse una bata impermeable en su } \\
\text { defecto estéril sobre el mameluco. Debe } \\
\text { quedar suelta, cómoda y anudarla con } \\
\text { nudo simple. }\end{array}$ & & & \\
\hline 9 & $\begin{array}{l}\text { Calzarse otro par de guantes de nitrilo o } \\
\text { látex sin talco encima. }\end{array}$ & & & \\
\hline 10 & $\begin{array}{l}\text { Una segunda persona verifica el sellado } \\
\text { correcto del traje, de lo contrario sella con } \\
\text { cinta adhesiva de papel. }\end{array}$ & & & \\
\hline
\end{tabular}

NOTA: DURANTE LA ATENCIÓN AL PACIENTE NO DEBE RECOLOCARSENADA. POR ESO LA IMPORTANCIA DE LA CORRECTA COLOCACIÓN DE LOS EPP. 


\section{LISTA DE CHEQUEO \\ RETIRO DEL EQUIPO DE PROTECCIÓN PERSONAL (EPP) PARA LA \\ ATENCIÓN DE PACIENTES CON COVID-19 \\ CUMPLIMIENTO OBLIGATORIO}

\section{DATOS DEL PERSONAL ASISTENCIAL EVALUADO} NOMBRES Y APELLIDOS:

OCUPACIÓN:

FECHA:

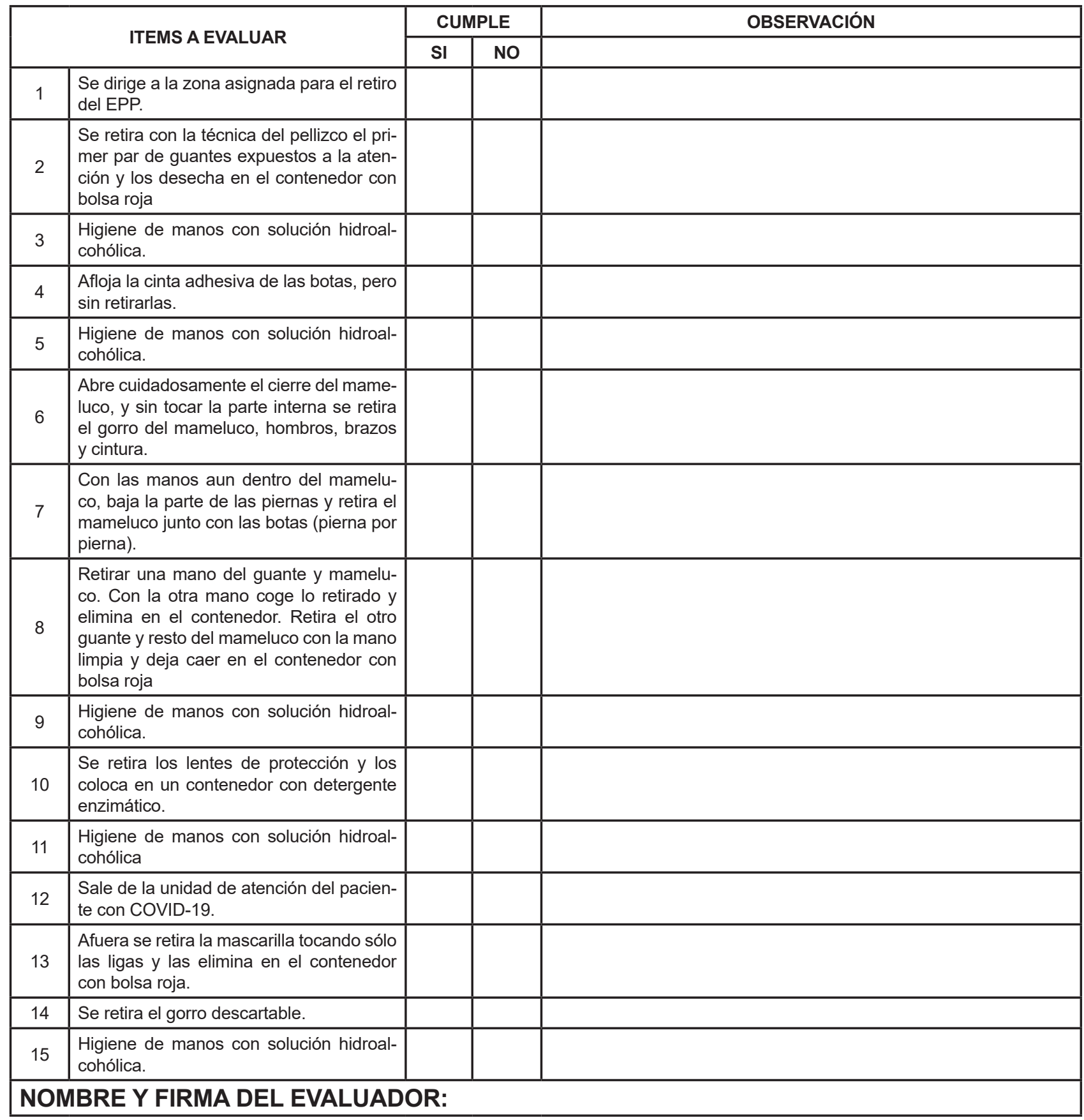

NOTA: PERSONAL SANITARIO DEBERA BAÑARSE ANTES DE IR A CASA. 